Conf- $950512-213$

UCRL-JC-119408

PREPRINT

\title{
Test Results of Pre-Production Prototype Distributed Ion Pump Design for the PEP-II Asymmetric B-Factory Collider
}

\author{
F.R. Holdener, D. Behne, D. Hathaway, \\ K. Kishiyama, M. Mugge, W. Stoeff, \\ K. van Bibber, C. Perkins, E.F. Daly, \\ E. Hoyt, M. Hoyt, M. Nordby, \\ J. Seeman, D. Wright
}

This paper was prepared for submittal to the

1995 Particle Accelerator Conference and International Conference

on High-Energy Accelerators, IEEE

Dallas, TX

May 1-5, 1995

April 24, 1995

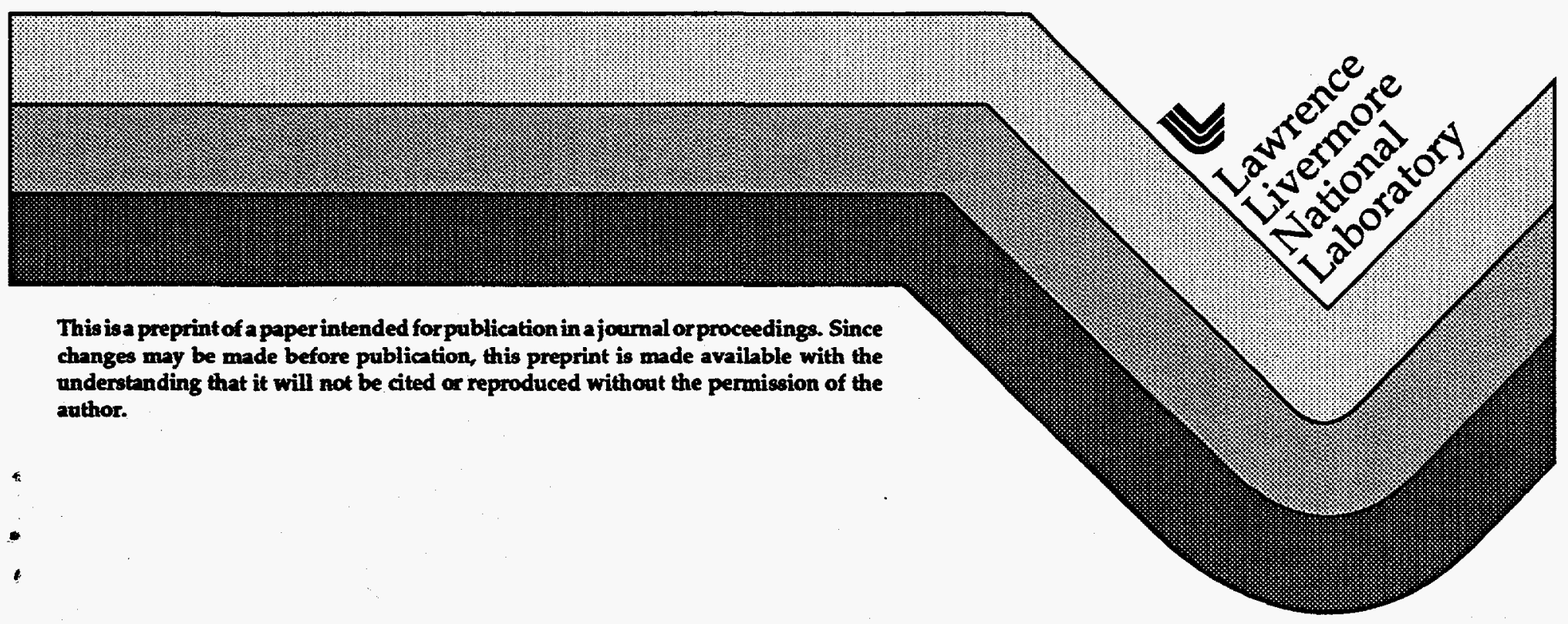




\section{DISCLAIMER}

This document was prepared as an account of work sponsored by an agency of the United States Government. Neither the United States Government nor the University of California nor any of their employees, makes any warranty, express or implied, or assumes any legal liability or responsibility for the accuracy, completeness, or usefulness of any information, apparatus, product, or process disclosed, or represents that its use would not infringe privately owned rights. Reference herein to any specific commercial product, process, or service by trade name, trademark, manufacturer, or otherwise, does not necessarily constitute or imply its endorsement, recommendation, or favoring by the United States Government or the University of California. The views and opinions of authors expressed herein do not necessarily state or reflect those of the United States Government or the University of California, and shall not be used for advertising or product endorsement purposes. 


\section{DISCLAIMER}

Portions of this document may be illegible in electronic image products. Images are produced from the best available original document. 


\title{
Test Results of Pre-Production Prototype Distributed Ion Pump Design for the PEP-II Asymmetric B-Factory Collider*
}

\author{
F.R. Holdener, D. Behne, D. Hathaway, K. Kishiyama, M. Mugge, W. Stoeffl, and K. van Bibber \\ Lawrence Livermore National Laboratory, Livermore, CA 94550 \\ C. Perkins, E.F. Daly, E. Hoyt, M. Hoyt, M. Nordby, J. Seeman, and D. Wright \\ Stanford Linear Accelerator Center, Stanford, CA 94309
}

\begin{abstract}
We have built and tested a plate-type pre-production prototype Distributed Ion Pump (DIP) for the PEP-II BFactory High Energy Ring (HER). The design has been simplified from an earlier design to use less materials and to reduce overall costs. Penning cell hole sizes of 15,18 , and 21 $\mathrm{mm}$ have been tested in a uniform magnetic field of $0.18 \mathrm{~T}$ to optimize pumping speed. The resulting final DIP design consisting of a 7-plate, $15 \mathrm{~mm}$ basic cell size anode was predicted to give the best pumping speed results for the actual varying magnetic field of the HER dipole. A description of the final optimized DIP design will be presented along with the test results of the pumping speed measurements.
\end{abstract}

\section{INTRODUCTION}

Operation of the PEP-II Asymmetric B-Factory collider in the $9 \mathrm{GeV}, 3 \mathrm{~A}$ mode or $12 \mathrm{GeV}, 1 \mathrm{~A}$ mode places significant pumping speed requirements on the High Energy Ring (HER) vacuum pumping system design. The high gas loads generated by the intense photon sychrotron radiation fan striking the copper vacuum chamber wall necessitate a vacuum pumping scheme that maintains the required HER pressures.

Using a gas desorption coefficient (eta) of $2 \times 10^{-6}$ molecules/photon[1], the calculated gas load at $1.48 \mathrm{~A}$ operation will be $5.3 \times 10^{-7}$ Torr $1 / \mathrm{s} / \mathrm{m}$ and $1.06 \times 10^{-6}$ Torr $\mathrm{I} / \mathrm{s} / \mathrm{m}$ at $3 \mathrm{~A}$. Average pressures required in the arcs are 5 nTorr at $1.48 \mathrm{~A}$ and $1 \mathrm{nTorr}$ at $3 \mathrm{~A}$. The vacuum system of a typical arc cell as seen in Figure 1 consists of two $6 \mathrm{~m}$ long dipole vacuum chambers and two quadrupole chambers $2 \mathrm{~m}$ long each. The quadrupole chambers will be pumped with 60 $1 / \mathrm{s}$ noble diode lumped ion pumps (LIPs). The dipole chamber at $6 \mathrm{~m}$ in length precludes pumping from the ends, thus distributed ion pumping is planned to offset the low conductance of the beam tube calculated at $40 \mathrm{l} / \mathrm{s} / \mathrm{m}$.

Quadrupole Chamber with $60 \mathrm{l} / \mathrm{s}$ Noble Diode LIP

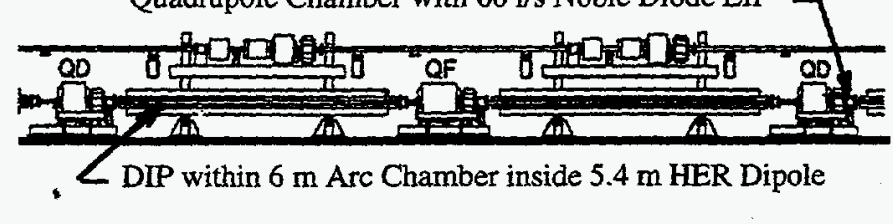

Figure 1. HER arc cell showing DIP

Distributed ion pumping was chosen based on calculations, rototype tests[2], and the reliability of previous operating 'EP-I designs. The ability to handle the quantities of the gas xpected to be generated from the high photon fluxes and uncertainties of the gas desorption properties of the final chamber material, C10100 OF copper, precluded the sole use of non-evaporable gettering as the distributed pumping method in the arc sections of the HER. However, a combined distributed ion pump/non-evaporable getter pump was considered and actually prototyped and tested as reported in a separate paper presented at this conference[3]. While distributed pumping speeds of $110 \mathrm{~J} / \mathrm{s} / \mathrm{m}$ were calculated as adequate to achieve the pressure requirement in the arcs, a pumping speed of $135 \mathrm{1} / \mathrm{s} / \mathrm{m}$ was set as a design goal to provide a $25 \%$ safety factor based on pumping speed alone given the latest screen design of calculated conductance of $450 \mathrm{1} / \mathrm{s} / \mathrm{m}$.

\section{PUMPING SYSTEM DESCRIPTION}

To achieve this pumping speed, distributed ion pump designs with plate-type anodes were chosen, as these were known to have relatively higher pumping speeds than that of the cylindrical type[4] i.e. the basic plate design has a higher conductance. The final production DIP design is shown in Figure 2.

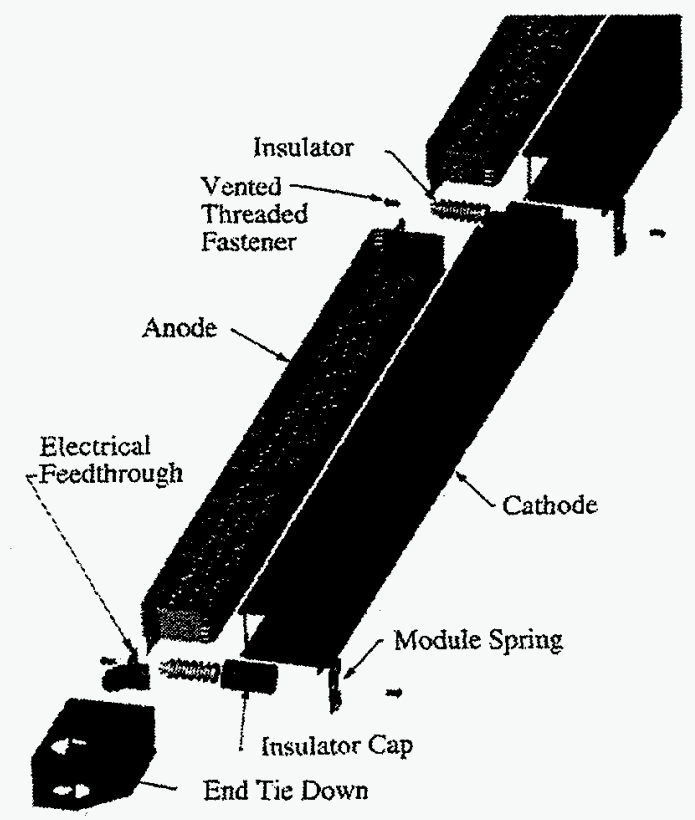

Figure 2. Exploded view of Production DIP Design

The pump shown is located in a channel space $50 \mathrm{~mm}$ high by $83 \mathrm{~mm}$ wide adjacent to a $6 \mathrm{~mm}$ specially machined copper screen plate formed to the same shape as the far side of the beam tube. The $6 \mathrm{~mm}$ thick screen consists of 6 symmetric, 
angled, $3 \mathrm{~mm}$ slots machined on the beam side with tightly packed holes aligned to the slots drilled through to the DIP side of the arc chamber. The DIP as shown in Figures 2 and 3 consists of a laser welded single piece $316 \mathrm{~L}$ stainless steel anode that has seven equally spaced plates. The five middle plates are $0.46 \mathrm{~mm}(0.018$ in) thick and the top and bottom plates are $0.64 \mathrm{~mm}(0.025 \mathrm{in})$ thick for increased overall stiffness as well as for increased durability in handling. On one end of the anode is a $0.64 \mathrm{~mm}(0.025 \mathrm{in})$ thick L-bracket for a stiff attachment point to the supporting shielded insulator. On the opposite end is a specially designed S-spring of $0.51 \mathrm{~mm}(0.020 \mathrm{in})$ thickness as the second attachment point that allows the anode to expand as thermal loads heat it during operation at high pressures, during the initial $200 \mathrm{C}$ dipole chamber bakeouts as well as for possible in-situ 95C bakeouts during maintenance cycles. The same spring allows for expansions and contractions during normal operational thermal variations at low pressures within the water-cooled copper arc chamber.

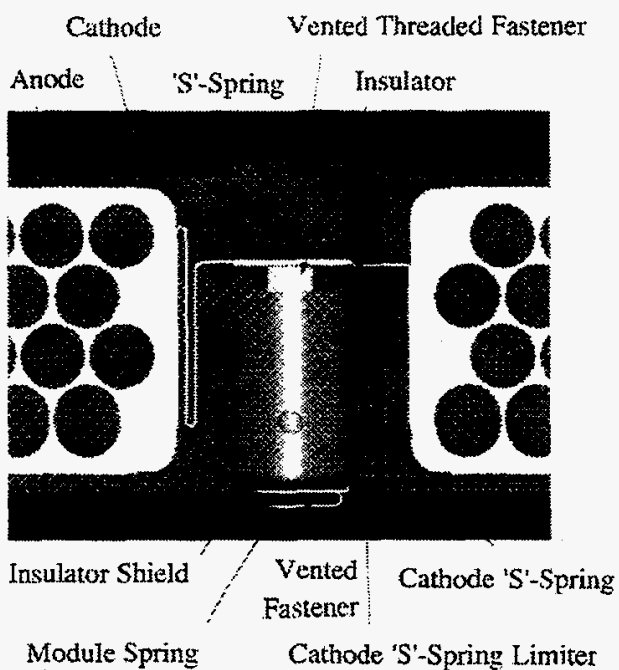

Figure 3 Normal Sectional View of a Typical Production DIP Joint at the Shielded $95 \%$ Alumina Insulator

The DIP cathode is also a single piece design of pure titanium. The unique U-channel design with large venting holes on the side away from the screen has allowed the cathode material thickness (as well as cost) to be significantly reduced from the original CDR design of $1.5 \mathrm{~mm}(0.059 \mathrm{in})$ to its present thickness of $0.89 \mathrm{~mm}(0.035$ in) while maintaining the same relative stiffness. While stiffness on the side away from the screen results from the U-shape geomety design, the stiffness on the edge next to the screen results from a formed V-shape at the cathode's edge. One end of the cathode is welded to a boxed shaped grounded support bracket that provides a rigid support to the grounded end of the shielded insulator. The opposite end of the cathode uses a $0.51 \mathrm{~mm}(0.020 \mathrm{in})$ thickness titanium S-spring similar to that of the anode with the added feature of an S-spring limiter. This limiter allows the entire seven module DIP string to be pulled into the arc dipole chamber without possible damage (i.e strained beyond normal material elastic limits) to either the anode or the cathode S-springs.
Another unique feature of the production DIP design, as can be seen in Figure 3, is the joint where a single shielded insulator supports two anode ends. This allows for a minimized I/P (DIP current/pressure) for the entire dipole string since there are only eight total shielded insulators for the seven total modules used per $5.4 \mathrm{~m}$ dipole. The only other insulators are in the fairly standard feed through arrangement on the end of the $6 \mathrm{~m}$ long dipole chambers. The module spring is designed to be bent to the right height matching the final chamber dimension to take up any horizontal play that may exist because of manufacturing tolerance stackups. All fasteners are non-magnetic stainless steel with standard venting to eliminate virtual leaks. After a DIP string assembly is together, all vented fasteners are torqued to $2.26 \mathrm{~N}-\mathrm{m}(20$ in-lbs) and tack welded in two places to prevent any possible future shorting of the DIP assembly by loosened fasteners. After meg-ohm, continuity, and hi-pot test (10kV for 1 minute) the DIP assembly will be permanently E-beam welded within its copper dipole chamber.

As seen in Figure 3, the forth row of penning cell holes have been elongated. This has been done to all seven plates in an identical manner to minimize production costs at the same time taking better advantage of the curved B-field in this area of the anode. Figure 4 shows an actual B-field plot map of a dipole cross section with the DIP positioned with the beam chamber centerline at nominal beam centerline. Physics requirements place the average beam chamber side of the dipole on centerline of the dipole poles. As can be seen, only the fourth row of cells sees any significant curvature of the Bfield. The arc chamber sagitta of plus/minus $9 \mathrm{~mm}$ has minimal effect on the average anode position along the length of the dipole, thus all anodes were made identical without the need for tabulations. This too helped keep material as well as assembly costs to a minimum.

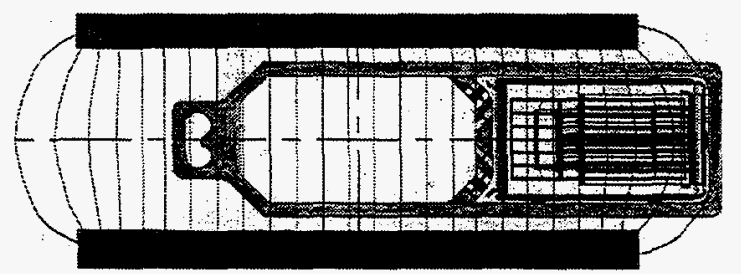

Figure 4 Production DIP within C10100 OF copper screened chamber showing center $0.18 \mathrm{~T}$ peak magnetic dipole field

\section{ANODE AND CATHODE PREPARATION}

After cleaning, the stainless and titanium parts were welded using standard SLAC UHV cleaning and handling practices. The titanium cathode was baked to $750 \mathrm{C}$ in the same turbo pumped evacuated chamber as the anode laser welded assembly that reached $450 \mathrm{C}$. Two days at temperature were required to reduce hydrogen generation to levels that were equivalent to the background hydrogen levels in the stainless chamber used for baking. After cooling the chamber to less than $100 \mathrm{C}$, the chamber was backfilled with argon to aid in a speedier cool down of the parts. For production this method will not be used because the argon background peak was seen in subsequent pumping speed tests. The small relative partial pressure of argon however was felt to have little effect on the final measured pumping speeds. For the production DIP 
parts, adequate cooling time will be allowed for parts to achieve $25 \mathrm{C}$ prior to backfilling chamber with nitrogen. In production, anodes and cathodes will be vacuum baked in separate UHV high temperature furnaces.

\section{TESTING DESCRIPTION AND RESULTS}

Prior to finalizing the production DIP design described in this paper, three earlier designed 1 meter long DIP modules described in previous two PAC papers[2,5] were tested in uniform B-field of the dipole center. The test results for the three hole size tested shown in Figure 5 are given in Table 1. The results confirmed our calculations for our geometry and B-field that based on H. Hartwig and Kouptsidis [6] and Malev and Trachtenberg [7] that the $15 \mathrm{~mm}$ hole size would give the maximum puming speed for HER requirements as shown in Figure 6. The seven plates were chosen over the five plate design because earlier measurements of $18 \mathrm{~mm}$ cells of both types distinctively showed that the 7-plate design gave superior performance. A 9-plate design was considered but time and dollars did not allow further testing although with the thin plate anode design additional pumping performance could be possible. Edge E-fields from the grounded screen and back side of the U-shape cathode are expected to have less effects on the penning cell's performance with increased number of plates. The tradeoff is of course decreased conductances.

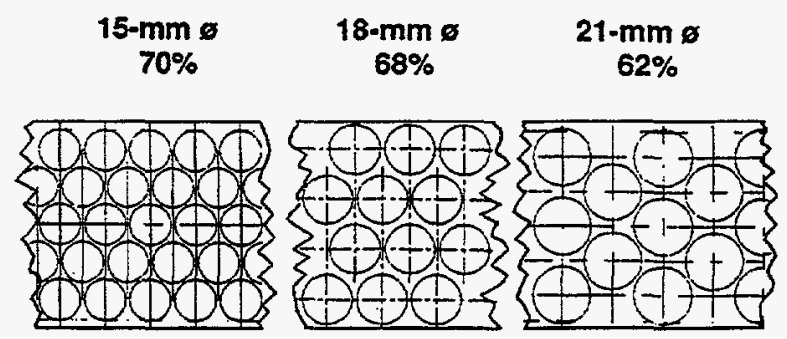

Figure 5 Three Anode Hole Patterns Tested

The results of pumping speed tests for the Pre-production DIP prototype in non-uniform field are $160 \mathrm{l} / \mathrm{s} /$ module or 206 $\mathrm{V} / \mathrm{s} / \mathrm{m}$ without the screen. Testing with the new screen have just started. Full production of this DIP design for the BFactory HER will start as soon as the first production units are functionality tested within the first production dipole. This is expected to be completed early this summer.

Table 1

Measured Pumping Speed -"Old": CDR DIP Design

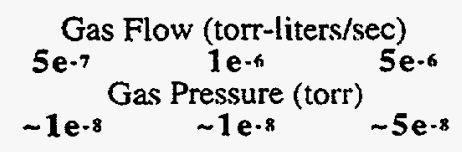

\begin{tabular}{|c|c|c|c|}
\hline DIP & Design & $\mathrm{N}_{2}$ Pumping Speed & $(\mathrm{sec} / \mathrm{m})$ \\
\hline 7-PL-18 & W/O SCR & $\begin{array}{l}186 \\
205 *\end{array}$ & 186 \\
\hline 7-PL-18 & W SCR* & $\begin{array}{l}103 \\
103\end{array}$ & $\begin{array}{l}204^{*} \\
100\end{array}$ \\
\hline S-PL-21 & W/O SCR & $\begin{array}{l}130 * \\
96 \\
103 *\end{array}$ & $\begin{array}{c}122^{*} \\
93 * \\
102 *\end{array}$ \\
\hline 5-PL-15 & W/O SCR & 188 & $\begin{array}{l}102^{*} \\
198\end{array}$ \\
\hline
\end{tabular}

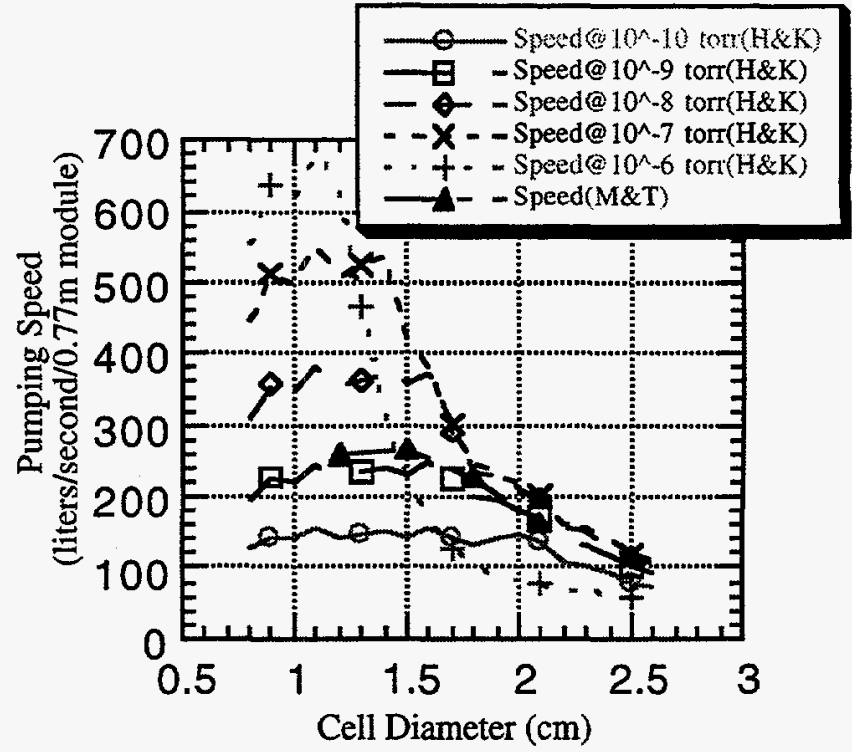

Figure 6 Plotted calculated curves for maximum pumping speeds for various cell sizes with a fixed anode width based on Hartwig-Kouptsidis[6] and Malev-Trachtenberg[7] for $0.18 \mathrm{~T}$ and 5500 volts

\section{RESULTS AND SUMMARY}

The result of $206 \mathrm{1} / \mathrm{s} / \mathrm{m}$ for the final production DIP design has more than met the design goal of $180 \mathrm{l} / \mathrm{s} / \mathrm{m}$. We are presently in the process of testing the screen to assure a conductance of $450 \mathrm{U} / \mathrm{s} / \mathrm{m}$ that will give us our design goal of $135 \mathrm{~V} / \mathrm{s} / \mathrm{m}$ for $\mathrm{N}_{2}$ as the final distributed pumping system for the HER.

\section{ACKNOWLEDGMENTS}

The authors wish to thank Mike McDaniel, Vernon Williamson and Pete Tirapelle the lead designers for the DIPs, Eric Ziebarth and his co-workers in the Laser Processes and Sheet Metal F Shops and Cleaning Specialists in Chris Steffani's of MMED. Jim Bowman, Al Lopez and Philip Keenan for significant roles in process step developments.

\section{REFERENCES}

[1] PEP-II, An Asymmetric B Factory, Conceptual Design Report, June 1993.

[2] Test Results of Distributed Ion Pump Designs for the PEP-II Asymmetric B Factory Collider, EPAC 1994 European particle Accelerator Conference.

[3] Test Results of a Combined Distributed Ion Pump/Nonevaporable Getter Pump Design Developed as a Proposed Alternate Pumping System for the PEP-II Asymmetric BFactory Collider, PAC 1995 Particle Accelerator Conference

[4] Y. Suetsugu and M. Nakagawa, Vacuum/Volume 42/1991, Great Britain

[5] Distributed Ion Pump Testing for PEP-II, Asymmetric B-Factory Collider, PAC 1993 Particle Accelerator Conference

[6] H. Hartwig and Kouptsidis, J. Vac. Sci. Technol., Vol $11,(6), 1974$

[7] M. D. Malev and E. M. Trachtenberg, Vacuum/volume 23/number 11, Pergamon Press Ltd, Great Britain.

* Work supported by the Department of Energy contract DE-AC03-76SF00515 (SLAC) and W-7405-ENG-48(LLNL) 